\title{
Steve Murphy, Mauvaise pensée du matin
}

\section{Mario Richter}

\section{(2) OpenEdition}

\section{Journals}

\section{Edizione digitale}

URL: https://journals.openedition.org/studifrancesi/46162

DOI: 10.4000/studifrancesi.46162

ISSN: 2427-5856

\section{Editore}

Rosenberg \& Sellier

\section{Edizione cartacea}

Data di pubblicazione: 1 octobre 2007

Paginazione: 470

ISSN: 0039-2944

\section{Notizia bibliografica digitale}

Mario Richter, «Steve Murphy, Mauvaise pensée du matin», Studi Francesi [Online], 152 (LI | II) | 2007, online dal 30 novembre 2015, consultato il 24 novembre 2021. URL: http://journals.openedition.org/ studifrancesi/46162 ; DOI: https://doi.org/10.4000/studifrancesi.46162

\section{Questo documento è stato generato automaticamente il 24 novembre 2021.}

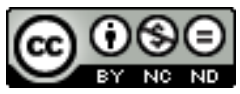

Studi Francesi è distribuita con Licenza Creative Commons Attribuzione - Non commerciale - Non opere derivate 4.0 Internazionale. 


\title{
Steve Murphy, Mauvaise pensée du matin
}

\author{
Mario Richter
}

\section{NOTIZIA}

STEVE MURPHY, Mauvaise pensée du matin, «Rimbaud vivant», n. 45, septembre 2006, pp. 39-81.

1 Uno dei testi più affascinanti, ma anche più misteriosi, di Rimbaud è l'oggetto di una nuova analisi molto articolata da parte del grande specialista Steve Murphy. Lo scopo principale dello studioso consiste nello smentire quanti hanno pensato e continuano a pensare che questa poesia del 1872 rappresenti un distacco di Rimbaud dall'impegno politico perseguito nell'anno precedente per una rinunciataria opzione unicamente formale ed estetica. Se nel 1987 il sottoscritto ha potuto rilevare che nella "Bonne pensée du matin" citata senza titolo in Une saison en enfer si assiste a una rivoluzionaria "étude" mirante a perlustrare lo spazio ignoto che si interpone fra i due termini dell'opposizione dualistica, Murphy (pur ammettendo il fondamento della precedente 'lettura') tenta di portare la natura rivoluzionaria del testo su un piano più direttamente legato agli avvenimenti socio-politici successivi allo sconvolgimento drammatico provocato dalla Commune. Non potendo ovviamente riprendere qui nei dettagli tutta la circostanziata e ricca argomentazione dell'articolo di Murphy, mi limito a sottolineare che, di fronte a questo testo, lo studioso costruisce una serie di ipotesi riconoscendo Parigi dietro Babilonia, Thiers dietro Nabuchodonosor e l'officina del lavoro operaio dietro la moschea «qui peut être - afferma testualmente l'A. - le symbole métonymiquement déplacé de l'obscurantisme catholique qui s'accomplirait dans la déformation et la défiguration de la réalité sociale». 